\title{
Smoking prevalence and risk factors for smoking in a population of United States Air Force basic trainees
}

\author{
C Keith Haddock, Robert C Klesges, Gerald W Talcott, Harry Lando, Risa J Stein
}

Department of Psychology, College of Arts and Sciences, University of

Missouri-Kansas City, Missouri, USA

C K Haddock

University of Memphis Prevention Center, Memphis, Tennessee

R C Klesges

Wilford Hall Medical Center, Lackland Air Force Base, Texas

$\mathrm{G}$ W Talcott

University of

Minnesota,

Minneapolis

Minnesota

H Lando

Rockhurst College, Kansas City, Missouri R J Stein

Correspondence to: Dr CK Haddock,

Department of Psychology, College of Arts and Sciences, College of Arts

University of

Missouri-Kansas City, 5100

Rockhill Road, Kansas City, chaddock@cctr.umkc.edu

\begin{abstract}
Objective-To provide a comprehensive assessment of smoking prevalence and risks for smoking in an entire population of United States Air Force (USAF) military basic trainees $(n=32144)$. Design-Population-based survey with every individual entering the USAF enlisted force from August 1995 to August 1996.

Setting-USAF Basic Military Training (BMT) facility at Lackland Air Force Base, Texas. All trainees were assessed during the first week of BMT.

Main outcome measures-A 53-item questionnaire was developed to assess four domains: demographics, smoking history, risk factors for smoking, and other health behaviours.

Results-Approximately $32 \%$ of the trainees smoked regularly before basic training and a small percentage of the trainees (7.6\%) described themselves as exsmokers. Men, Euro-Americans, and those from lower educational backgrounds were more likely to smoke than other trainees. On average, smokers had smoked for approximately four years and had low nicotine dependence scores. Individuals who had smoked before BMT were more likely to use other drugs (such as alcohol, binge drinking, smokeless tobacco), and were less physically active than never-smokers. These findings were particularly strong for those who smoked up to basic training but were also evident for ex-smokers.
\end{abstract}

Conclusions-Smoking is a prevalent risk factor among individuals entering the USAF. Furthermore, smoking was related to other risk factors believed to lower military readiness, including alcohol use and decreased physical activity. Comprehensive tobacco control policies aimed at reducing smoking among military trainees are needed.

(Tobacco Control 1998;7:232-235)

Keywords: military trainees, smoking prevalence, United States

\section{Introduction}

There are now tens of thousands of studies linking cigarette smoking to increased morbid- ity and mortality from cardiovascular diseases, various forms of cancer, and chronic obstructive pulmonary disease. ${ }^{1}$ It is estimated that annually in the United States, smoking is causally related to 170000 deaths from cardiovascular disease, 130000 deaths from cancer, and 50000 deaths from chronic obstructive pulmonary disease. ${ }^{2}$ Given the severe health effects of smoking, the United States military has become increasingly concerned about the rate of smoking among its personnel. Smoking and its related health problems cost the military nearly $\$ 1$ billion each year among active duty personnel alone and clearly impacts the health and safety of combat troops.

Unfortunately, comprehensive studies of the smoking patterns and predictors of tobacco use among those recruited for military service are lacking. The purpose of this study is to provide a comprehensive assessment of smoking prevalence and risk factors for smoking in an entire population $(n>32000)$ of United States Air Force (USAF) basic military trainees. A comprehensive examination of tobacco use among young adults entering military service should provide important data for military tobacco control efforts.

\section{Methods}

SUBJECTS, DEFINITIONS, AND PROCEDURE A total of 32144 individuals who completed basic military training (BMT) from August 1995 to August 1996 were included in the study. Because a smoking cessation programme was incorporated as part of BMT, it became a part of the instructional mission of the Air Force and therefore was a required training experience. The human subjects protocol for this project was reviewed by the Air Force Surgeon General's Office CID (Clinical Investigations Directorate), the granting institute, and the university receiving funding (University of Memphis), and was approved as exempt by all three. Because of a comprehensive ban on tobacco use during BMT, all participants were abstinent during the study. Table 1 presents demographic data for this population, stratified by gender.

A 53-item questionnaire, developed for use in this study, was administered in the first week of basic training in a group setting in "flights" of approximately 50 basic trainees. All 
Table 1 Population demographics

\begin{tabular}{|c|c|c|c|}
\hline Factor & Men & Women & All participants \\
\hline Number of participants & 23912 & 8232 & 32144 \\
\hline Mean age (SD) (years) & $19.81(2.22)$ & $19.89(2.55)$ & $19.85(2.31)$ \\
\hline Married (\%) & 12.1 & 13.0 & 12.3 \\
\hline \multicolumn{4}{|l|}{ Ethnic status (\%) } \\
\hline Euro-American & 72.4 & 62.2 & 69.8 \\
\hline African-American & 12.0 & 20.0 & 14.0 \\
\hline Hispanic American & 8.3 & 9.2 & 8.5 \\
\hline Other^ & 7.3 & 8.6 & 7.7 \\
\hline \multicolumn{4}{|c|}{ Annual household income $(\$) \dagger(\%)$} \\
\hline$\leqslant 20000$ & 22.4 & 28.1 & 23.9 \\
\hline $21000-50000$ & 50.3 & 49.3 & 50.1 \\
\hline $51000-80000$ & 20.7 & 17.9 & 26.0 \\
\hline$>80000$ & 6.6 & 4.7 & 6.0 \\
\hline \multicolumn{4}{|l|}{ Education level (\%) } \\
\hline High school degree & 64.3 & 54.6 & 61.8 \\
\hline Some college $\neq$ & 33.2 & 42.3 & 35.6 \\
\hline 4-Year college degree & 2.1 & 2.8 & 2.3 \\
\hline Graduate training or degree & 0.4 & 0.3 & 0.3 \\
\hline
\end{tabular}

*The "Other" ethnic group category was created because of the small number of individuals who comprised the remaining ethnic groups.

†Defined as the total income of the household where the basic trainee lived in the year before Basic Military Training.

$\ddagger$ Includes those who attained a 2-year college degree.

questionnaires were checked for thoroughness before the flight departing. The measure collected information from four general domains: demographic information, history of tobacco use, factors though to be associated with smoking onset/relapse, and other health risk factors. Because data sets collected on military personnel could be seized or subpoenaed, we did not want to collect data that could potentially endanger the participants' careers. Thus, opinions regarding drug use (and other illegal behaviours) were assessed. Due to numerous quality control checks and the fact that the questionnaire was given as part of BMT, there were virtually no missing data. A six-week test/retest reliability assessment was performed on all items using a randomly selected subgroup of basic trainees ( $\mathrm{n}=7080)$. Considering the relatively long lag between assessments and the unusually stressful nature of this time period (basic military training), the questionnaire demonstrated surprisingly strong stability. The median test/retest Pearson correlation was 0.73 .

Table 2 Tobacco use characteristics for current smokers

\begin{tabular}{|c|c|c|c|}
\hline & $\begin{array}{l}\text { All smokers } \\
n=7998(\%)\end{array}$ & $\begin{array}{l}\text { Men } \\
n=6054(\%)\end{array}$ & $\begin{array}{l}\text { Women } \\
n=1994(\%)\end{array}$ \\
\hline \multicolumn{4}{|c|}{ Daily cigarette consumption } \\
\hline$\leqslant 10$ & 28.7 & 26.5 & 35.5 \\
\hline $11-20$ & 46.5 & 46.6 & 46.2 \\
\hline $21-30$ & 19.5 & 20.7 & 15.6 \\
\hline$\geqslant 31$ & 5.2 & 6.0 & 2.7 \\
\hline \multicolumn{4}{|c|}{ Fagerström dependence level } \\
\hline Very low & 36.1 & 34.5 & 41.1 \\
\hline Low & 28.4 & 28.4 & 28.3 \\
\hline Medium & 13.1 & 13.4 & 12.3 \\
\hline High & 16.7 & 17.4 & 14.5 \\
\hline Very high & 5.7 & 6.3 & 3.8 \\
\hline \multicolumn{4}{|l|}{ Cigarette type } \\
\hline Regular & 49.6 & 54.3 & 35.2 \\
\hline Light & 44.6 & 40.1 & 58.7 \\
\hline Ultralight & 2.0 & 1.4 & 3.9 \\
\hline No usual brand & 3.7 & 4.2 & 2.2 \\
\hline \multicolumn{4}{|l|}{ Smokeless tobacco use } \\
\hline Prevalence & 4.6 & 6.0 & 0.2 \\
\hline \multicolumn{4}{|c|}{ I'm confident I'll stay quit* } \\
\hline Strongly agree & 14.9 & 15.8 & 12.0 \\
\hline Agree & 21.0 & 20.9 & 21.3 \\
\hline Neutral & 45.0 & 43.8 & 48.8 \\
\hline Disagree & 11.3 & 10.8 & 12.6 \\
\hline Strongly disagree & 7.8 & 8.7 & 5.3 \\
\hline
\end{tabular}

^Item phrased "Once I get out of BMT, I am confident that I will be able to stay quit permanently.”
For the purposes of this study, "neversmoker" refers to those airmen who reported never regularly smoking cigarettes ("I never smoked a cigarette before Basic Military Training" or "I smoked on one or two occasions, but never regularly (at least one per day) before Basic Military Training"). "Ex-smokers" refers to those airmen who reported smoking at least one cigarette each day before BMT, but who quit smoking before training ("I smoked regularly (at least one per day), but quit before Basic Military Training"). "Smokers" refers to trainees who smoked continually up to entry into the Air Force ("I smoked regularly (at least one per day) and smoked right up to the point I entered Basic Military Training").

Because of the very large sample size and the impracticality of collecting biochemical data in basic training, self-reports of smoking were collected. Research on self-reports of smoking indicate that they are highly accurate for virtually all assessment and intervention studies. ${ }^{4}$ Further, the smoking status of all subjects was considered confidential information and the Air Force did not penalise smokers in any manner solely because of their smoking status.

\section{APPROACH TO DATA ANALYSIS}

In the analyses testing predictors of smoking status, two logistic regression models were constructed. The first model compared neversmokers with ex-smokers whereas the second contrasted never-smokers with smokers. ${ }^{5}$ The following approach was used to select predictors of smoking status. First, variables believed to be theoretically important determinants of smoking status were identified. These factors included social influences on smoking (percentage of friends who smoke, predicted percentage of Air Force personnel who smoke, rating of the social attractiveness of smoking), health behaviours and substance use (self-rated physical activity level, total alcohol use, frequency of binge drinking, smokeless tobacco use, attitudes toward illicit drug use, level of concern about body weight, frequency of dieting to lose weight), and measures of risk taking and rebelliousness (enjoyment of taking safety risks, frequency of seatbelt use, self-rated level of rebelliousness). Next, a careful examination of the univariate relationship between the dependent variable and potential independent variables was conducted. Also, the correlation matrix of potential predictors was explored to eliminate redundancy among predictors (suppressor variables). ${ }^{6}$ Variables retained after these screening procedures were entered into a logistic regression model along with demographic factors. Finally, given the interest in gender as a moderating variable in substance abuse research and as a factor in military training, interactions between gender and significant predictors of smoking status were tested. Due to the large sample size of this data set and the corresponding high statistical power, a $99 \%$ confidence interval was used as the statistical significance criterion throughout the variable selection process. 
Table 3 Logistic regression model comparing never-smokers to ex-smokers

\begin{tabular}{lcl}
\hline Variable & $\begin{array}{l}\text { Odds } \\
\text { ratio }\end{array}$ & $\begin{array}{l}\text { 99\% Confidence } \\
\text { interval }\end{array}$ \\
\hline Age & 1.08 & $1.04-1.11$ \\
Gender & 1.23 & $1.06-1.43$ \\
Ethnicity (vs Euro-Americans) & & \\
$\quad$ African-American & 0.35 & $0.27-0.45$ \\
$\quad$ Hispanic-Americans & 0.76 & $0.61-0.95$ \\
$\quad$ Other & 0.80 & $0.63-1.01$ \\
Income level & 1.02 & $0.95-1.10$ \\
Education level & 0.84 & $0.76-0.94$ \\
Marital status & 1.49 & $1.24-1.80$ \\
Percentage of friends who smoke & 1.89 & $1.78-2.01$ \\
Smoking is socially attractive & 2.19 & $2.06-2.32$ \\
Alcohol use & 1.29 & $1.21-1.38$ \\
Smokeless tobacco use & 1.94 & $1.61-2.34$ \\
\hline
\end{tabular}

Dependent variable coded $1=$ ex-smoker; $0=$ never-smoker. Gender coded $0=\operatorname{man} ; 1=$ woman. Marital status coded $0=$ $1=<20 \% ; 2=20-49 \% ; 3=50-79 \% ; 4=\geqslant 80 \%$. Social attractiveness of smoking rated on a 5 -point scale from $1=$ strongly disagree to $5=$ strongly agree. Alcohol use coded as $1=$ no use; $2=$ drink a few times per year, $3=$ drink a few times per month, $4=$ drink a few times per week, $5=$ drin every day. Smokeless tobacco use coded $0=$ non-user; $1=$

\section{Results}

PREVALENCE OF SMOKING

Basic trainees who smoked regularly before BMT comprised $32.5 \%(n=10440)$ of the population. A small percentage of the basic trainees $(7.6 \% ; \mathrm{n}=2442)$ reported having quit smoking before BMT. A large percentage of basic trainees $(46 \%)$ indicated having never smoked a cigarette whereas $22 \%$ said they had experimented with smoking but never smoked regularly (at least one per day). Smokers (those who smoked up to BMT; $n=7998$ ) reported that they had smoked for an average of 4.13 years $(\mathrm{SD}=2.88)$.

Table 2 presents tobacco use characteristics for smokers. Outcomes from the Fagerström Test for Nicotine Dependence ${ }^{7}$ indicated that smokers typically had low addiction scores. Most smokers in this population smoked one pack or less each day, and preferred either regular or light cigarette brands. Although most smokers were undecided as to whether

Table 4 Logistic regression model comparing never-smokers to smokers

\begin{tabular}{lll}
\hline Variable & Odds Ratio & $\begin{array}{l}99 \% \text { Confidence } \\
\text { interval }\end{array}$ \\
\hline Age & 1.09 & $1.06-1.12$ \\
Gender & 0.60 & $0.37-0.99$ \\
Ethnicity (vs Euro-Americans) & & \\
$\quad$ African-American & 0.37 & $0.31-0.45$ \\
$\quad$ Hispanic-Americans & 0.52 & $0.43-0.63$ \\
$\quad$ Other & 0.68 & $0.56-0.82$ \\
Income level & 1.12 & $1.06-1.19$ \\
Education level & 0.73 & $0.67-0.80$ \\
Marital status & 1.37 & $1.17-1.61$ \\
Percentage of friends who smoke & 2.65 & $2.52-2.79$ \\
Percentage of Air Force personnel who smoke & 0.82 & $0.76-0.89$ \\
Smoking is socially attractive & 3.61 & $3.43-3.79$ \\
Alcohol use & 1.33 & $1.25-1.42$ \\
Frequency of binge drinking ( $\geqslant 8$ drinks/day) & 1.15 & $1.06-1.24$ \\
Smokeless tobacco use & 1.94 & $1.61-2.34$ \\
Self-rated physical activity level & 0.80 & $0.76-0.85$ \\
Frequency of weight concerns & 0.83 & $0.76-0.91$ \\
Frequency of dieting to lose weight & 0.82 & $0.75-0.90$ \\
Gender $\times$ frequency of binge drinking & 1.16 & $1.01-1.35$ \\
Gender $\times$ self-rated physical activity level & 1.15 & $1.03-1.27$ \\
Gender $\times$ frequency of weight concerns & 1.19 & $1.04-1.36$ \\
\hline Percenta of friends who smoke coded as & &
\end{tabular}

Percentage of friends who smoke coded as $1=>20 \% ; 2=20-49 \% ; 3=50-79 \% ; 4=\geqslant 80 \%$. Frequency of binge drinking coded as $1=$ never; $2=$ a few times per year; $3=$ a few times per month; $4=$ a few times per week; $5=$ every day. Self-rated physical activity coded on a 5 -point month; $4=$ a few times per week; $5=$ every day. Self-rated physical activity coded on a 5 -point others. Frequency of weight concerns and frequency of dieting to lose weight coded on a Likert others. Frequency of weight concerns and frequency of dieting to lose weight coded on a Likert
scale with four categories: never; sometimes; frequently; and always. Remaining variables coded scale with four
as in table 3 . they could remain abstinent following BMT, more agreed $(35.9 \%)$ than disagreed $(19.1 \%)$ that they could remain abstinent after training. Compared with male smokers, female smokers generally reported smoking fewer cigarettes per day, being less dependent, and being more likely to use light or ultralight cigarettes.

RISK FACTORS FOR SMOKING

Never-smokers vs ex-smokers

A logistic regression model was developed which attempted to separate basic trainees who were never-smokers from those who had quit smoking before BMT. As can be seen in table 3, five of the six demographic factors distinguished never-smokers from ex-smokers. Ex-smokers tended to be older, EuroAmerican, married, and to have less education than basic trainees who had never regularly smoked. As the percentage of friends who smoked increased, participants were $89 \%$ more likely to be an ex-smoker than a never-smoker. Similarly, as the participants' rating of the social attractiveness of smoking increased, they were 2.2 times more likely to be an ex-smoker than a never-smoker. Finally, increases in two measures of substance use-total alcohol use and smokeless tobacco use-were significantly related to increases in the likelihood of being an ex-smoker compared with a never-smoker. Gender did not significantly moderate the relationship between any of the predictors and smoking status.

\section{Never-smokers vs current smokers}

The final logistic regression model was developed to separate basic trainees who were never-smokers from those who were regular smokers up to BMT. As can be seen in table 4, older basic trainees, men, Euro-Americans, individuals with less education, those from higher income households, and those who were married were more likely to be smokers. As the percentage of friends who smoked increased, basic trainees were nearly 2.7 times more likely to smoke. In contrast, smokers predicted that the percentage of Air Force personnel who smoke was less than that predicted by never-smokers. The strongest predictor of smoking status was the participant's rating of the social attractiveness of smoking. As ratings of the social attractiveness of smoking increased, participants were 3.6 times more likely to be smokers.

Several substance use and health behaviour factors significantly predicted smoking status. Smokers reported drinking more alcohol and had more frequent binge-drinking episodes than never-smokers. Smokers also characterised themselves as less physically active, engaging in less dieting, and having weight concerns less frequently than never-smokers. However, three of these factors interacted with gender in the relationship to smoking status. Follow-up analyses indicated that physical activity level was more strongly related to smoking status for men (odds ratio $(\mathrm{OR})=0.77 ; 99 \%$ confidence interval $(\mathrm{CI})=0.74$ to 0.80 ) than for women $(\mathrm{OR}=0.90 ; 99 \% \mathrm{CI}=0.84$ to 0.95$) . \mathrm{In}$ contrast, frequency of binge drinking was more 
strongly related to smoking status for women $(\mathrm{OR}=2.67 ; 99 \% \mathrm{CI}=2.43$ to 2.98$)$ than for men $(\mathrm{OR}=2.07 ; 99 \% \mathrm{CI}=1.98$ to 2.16$)$. Finally, although frequency of weight concerns lowered the likelihood of smoking in men $(\mathrm{OR}=0.80 ; 99 \% \mathrm{CI}=0.76$ to 0.85$)$, it was associated with a higher likelihood of smoking in women $(\mathrm{OR}=1.14 ; 99 \% \mathrm{CI}=1.06$ to $1.22)$.

\section{Discussion}

The results of this study suggest that smoking is a prevalent health risk behaviour among USAF enlistees. Overall, $32.5 \%$ of basic trainees smoked regularly before BMT and a small percentage $(7.6 \%)$ of basic trainees described themselves as ex-smokers. Further, this study found that among basic trainees, individuals from minority ethnic backgrounds were far less likely to smoke than Euro-Americans. The latter finding is consistent with recent surveys that suggest that young minorities have a lower prevalence of smoking than non-minorities. However, this is confusing in that the national rates of smoking are higher in some minority groups, especially among African-American and Hispanic-American men. ${ }^{8}$ This raises the possibility of late-onset smoking, which has been documented in some ethnic groups such as African-Americans. Future studies should examine whether minorities are at risk for lateonset smoking and, if so, should determine factors leading to late smoking initiation.

Consistent with surveys of civilian populations, male gender and a lower educational background increased the likelihood of smoking. ${ }^{9-12}$ However, the finding that smokers tended to be from households with higher incomes than never-smokers is inconsistent with previous research. ${ }^{13}$ It is possible that young adults from higher income families who nonetheless decide to join the enlisted ranks of the military represent a unique group in terms of health and safety habits. The relationship between household income and the likelihood of smoking deserves attention in future research with military populations.

The strongest predictors of smoking status among USAF basic trainees were social. Specifically, having more friends who smoke and viewing smoking as more socially attractive significantly increased one's risk of smoking. These findings are consistent with studies demonstrating the potent impact of social factors on smoking onset and maintenance among young adults. ${ }^{14-16}$ Given that USAF basic trainees form new friendships upon entering the military and that smoking is increasingly viewed negatively by the armed services, BMT provides a unique setting to address social influences on smoking.

This study adds to a growing literature that suggests that smokers often engage in a cluster of unhealthy behaviours. Specifically, basic trainees who had smoked before basic training were more likely to use other drugs-for example, alcohol, binge drinking, smokeless tobacco-and were less physically active. These finding were particularly strong for those who smoked up to basic training but were also evident for ex-smokers. Given that the military has identified substance abuse and lack of physical activity as barriers to military readiness, this study suggests that smokers may be less fit for military duty. ${ }^{17-19}$ Future studies examining the relationship between smoking and actual military performance and discharge rates are needed.

The nature of the USAF BMT population may limit the generalisability of the findings. Specifically, this population consisted entirely of young adults who had volunteered for military service and was well represented with ethnic minorities. Population-based research examining smoking prevalence and risks for smoking in similar cohorts (such as other military services) is needed to validate the results of this study.

This study was supported by a National Institutes of Health grant (HL-53478). The views expressed in this article are the authors and do not necessarily reflect the official position of USAF Basic Training, the Department of Defense, or the United States Government.

1 US Department of Health and Human Services. The health benefits of smoking cessation. A report of the Surgeon General, 1990. Rockville, Maryland: Public Health Service, Centers (DHHS Publication No (CDC) 90-8416.)

2 US Department of Health and Human Services. The health consequences of smoking: nicotine addiction. A report of the Surgeon General, 1988. Rockville, Maryland: Public Health Service, Centers for Disease Control, Office on Smoking and Health, 1988. (DHHS Publication No (CDC) 88-8406.)

3 US Department of Defense. Economic consequences of tobacco use for the Department of Defense. Unpublished technical report, US Department of Defense, Washington, DC, 1996.

4 Velicer WF, Prochaska JO, Rossi JS, et al. Assessing outcome in smoking cessation studies. Psychol Bull 1992;111:23-41.

5 Hosmer DW, Lemeshow S. Applied logistic regression. New York: Wiley, 1989.

6 Conger AJ. A revised definition of suppressor variables. Educ Psychol Meas 1974;34:35-46.

7 Heatherton TF, Kozlowski LT, Frecker RC, et al. The Fagerström Test for Nicotine Dependence: A revision of the Fagerström Tolerance Questionnaire. Br f Addict 1991; 86:1119-27.

8 Chen VW. Smoking and the health gap in minorities. Ann Epidemiol 1993;3:159-64.

9 Grunberg NE, Winders SE, Wewers ME. Gender differences in tobacco use. Health Psychol 1991;10:143-53.

10 US Centers for Disease Control and Prevention. Prevalence of smoking by area of residence - Missouri, 1989-1991. MMWR 1995;44:494-7.

11 US Centers for Disease Control and Prevention. Cigarette smoking among adults-United States, 1994. MMWR 1996;45:588-90.

12 Metropolitan Insurance Companies. Cigarette smoking among adults, 1985-1990, and smoking among selected occupational groups, 1990. Stat Bull 1992;73:12-19.

13 US Department of Health and Human Services. Preventing tobacco use among young people. A report of the Surgeon General, 1994. Atlanta, Georgia: Public Health Service, Centers for Disease Control and Prevention, Office on Smoking and Health, 1994. (US Government Printing Office No S/N 017-001-00491-0.)

14 Botvin GJ, Epstein JA, Schinke SP, et al. Predictors of cigarette smoking among inner-city minority youth. Dev Behav Pediatr 1994;15:67-73.

15 Dusenbury L, Kerner JF, Baker E, et al. Predictors of smoking prevalence among New York Latino youth. Am f Public Health 1992;82:55-8.

16 Stanton WR, Mahalski PA, McGee R, et al. Reasons for smoking or not smoking in early adolescence. Addict Behav 1993;18:321-9

17 Allen J, Mazzuchi J. Alcohol and drug abuse among American military personnel: Prevalence and policy implications. Mil Med 1985;150:250-5.

18 Snoddy RO, Henderson JM. Predictors of basic infantry training success. Mil Med 1994;159:616-22.

19 Stout RW, Parkinson MD, Wolfe WH. Alcohol-related mortality in the US Air Force, 1990. Am $\mathcal{F}$ Prev Med 1993;9:220-3. 